\title{
Erratum to: Atmospheric and Space Sciences: Ionospheres and Plasma Environments
}

\section{Erratum to:}

E. Yigit, Atmospheric and Space Sciences: Ionospheres and Plasma Environments, SpringerBriefs in Earth Sciences, https://doi.org/10.1007/978-3-319-62006-0

The original version of the book was inadvertently published with incorrect author name "E. Yigit" which has to be corrected as "E. Yiğit" in source line of all chapters. The erratum book has been updated with the change 